Reprod. Nutr. Dévelop., 1986, 26 (1 B), 363-364.

\title{
Evolution du cholestérol lié aux lipoprotéines légères chez la vache en début de lactation et relation avec l'infiltration lipidique du foie
}

\author{
A. MAZUR, Elyett GUEUX, S. BAZIN (*), Y. RAYSSIGUIER
}

I.N.R.A., Theix 63122 Ceyrat, France

(*) I.T.E.B., 149, rue de Bercy, 75595 Paris cedex 12.

Summary. The cholesterol associated with low density lipoproteins has been estimated in dairy cows as the difference between total cholesterol and HDL cholesterol obtained by precipitation. This fraction was significantly decreased in early lactation compared to late pregnancy or to 4 to 6 weeks post-calving.

La précipitation des fractions lipoprotéiques légères permet d'évaluer rapidement le cholestérol associé aux lipoprotéines de haute densité (HDL cholestérol). Cette technique a été appliquée chez la vache laitière pour déterminer l'origine de la diminution de la cholestérolémie associée au démarrage de la lactation.

Matériel et méthodes. L'étude a été réalisée chez 41 vaches laitières Pie Noires $(6640 \mathrm{~kg}$ de lait par lactation), d'un même troupeau, et recevant une alimentation à base d'ensilage de maïs. Des prélèvements sanguins ont été effectués 4 semaines avant le vêlage, 10 jours, 4 et 6 semaines après le vêlage. Sur 10 de ces vaches prises au hasard, des biopsies hépatiques ont été réalisées 10 jours et 6 semaines post partum. Les méthodes enzymatiques ont permis le dosage du cholestérol total plasmatique et du HDL cholestérol après précipitation au phosphotungstate de sodium associé au chlorure de magnésium ainsi que des triglycérides hépatiques.

Résultats et discussion. Par rapport aux autres périodes étudiées, le démarrage de la lactation est associé à une diminution significative du cholestérol total. Cette diminution résulte essentiellement de celle des fractions légères représentées par la différence cholestérol total-HDL cholestérol. Dix jours après le vêlage, cette différence est en effet significativement plus faible $(P<0,001)$ qu'aux autres périodes étudiées. Ce résultat apparaît particulièrement si l'on compare le début de la lactation à la fin de la gestation. Après le vêlage, le cholestérol total diminue significativement en dépit d'une augmentation significative du HDLcholestérol.

II existe une certaine imprécision dans la détermination du cholestérol des fractions légères puisque le mode de calcul fait intervenir la différence des valeurs obtenues pour le cholestérol total et le HDL-cholestérol et que le taux des lipoprotéines légères est particulièrement faible chez le Ruminant. Toutefois, la forte diminution du cholestérol des fractions légères en début de lactation, est en accord avec les résultats obtenus précédemment par ultracentrifugation, (Raphaël, Dimick et Puppione, 1973 ; Mazur et al., 1986) méthode de référence. 
Cette diminution intervient chez les vaches présentant un faible taux d'infiltration lipidique du foie $(22,5 \pm 4,9$ et $6,0 \pm 0,3 \mathrm{mg} / \mathrm{g}$ poids frais 10 jours et 6 semaines après le vêlage) mais pourrait être accentuée lors de stéatose sévère (Rayssiguier et al., 1986).

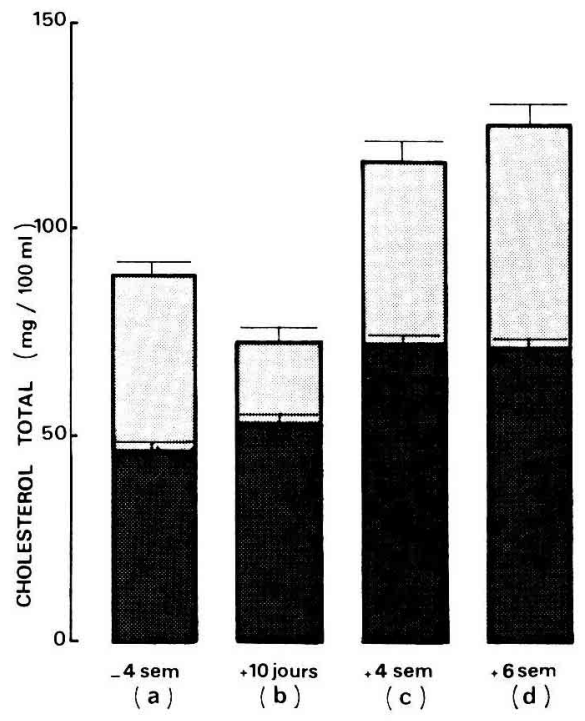

FIG. 1. - Evolution de la cholestérolémie chez la vache laitière.

cholestérol HDL ;

cholestérol des lipoprotéines légères.

Moyenne \pm erreur type $(n=41)$. Différences significatives entre les différentes périodes $(P<0,05)$. Cholestérol total : a-b, c, d ; b-c, d. Cholestérol HDL : a-b, c, d ; b-c, d. Cholestérol des lipoprotéines légères : $a-b, d ; b-c, d$.

Mazur A., Gueux E., Chilliard Y., Rayssiguier Y., 1986. Evolutions des lipides et lipoprotéines plasmatiques chez la vache en début de lactation. Reprod. Nutr. Dévelop., 26, 357-358.

Raphaël B. C., Dimick P. S., Puppione D. L., 1973. Lipid characterization of bovine serum lipoproteins throughout gestation and lactation. J. Dairy Sci., 56, 1025-1032.

Rayssiguier Y., Mazur A., Reid I. M., Roberts C. J., Gueux E., 1986. Modifications des lipoprotéines plasmatiques associées à la stéatose hépatique chez la vache en début de lactation. Reprod. Nutr. Dévelop., 26, 361-362. 